\title{
Effect of Degree of Cure on Sandwich Structural Capacitor Using Ion-Conductive Polymer with Carbon Fabric Skins
}

\author{
Akira Todoroki \\ Department of Mechanical Sciences of Engineering, Tokyo Institute of Technology, Tokyo, Japan \\ Email: atodorok@ginza.mes.titech.ac.jp
}

How to cite this paper: Todoroki, A. (2016) Effect of Degree of Cure on Sandwich Structural Capacitor Using Ion-Conductive Polymer with Carbon Fabric Skins. Open Journal of Composite Materials, 6, 112-120.

http://dx.doi.org/10.4236/ojcm.2016.64011

Received: August 17, 2016

Accepted: September 16, 2016

Published: September 19, 2016

Copyright $\odot 2016$ by authors and Scientific Research Publishing Inc. This work is licensed under the Creative Commons Attribution International License (CC BY 4.0).

http://creativecommons.org/licenses/by/4.0/

\section{(c) (i) Open Access}

\begin{abstract}
Structural capacitors are composite structures that function as energy storage capacitors. An electric double-layer capacitor with a composite structure using a solid polymer electrolyte matrix with a glass fiber fabric separator has recently been developed. In the present study, new foam core sandwich structure is adopted and the effect of the degree of cure is experimentally investigated. Carbon fiber fabric cloth is used as electrodes, and the polystyrene foam core is used as separator. Material system of Poly Ethylene Glycol DiGlycidyl Ether (PEGDGE) with Lithium bisTriFluoromethane Sulfonyl Imide (LiTFSI) and hardener of TriEthylene TetrAmine (TETA) is adopted as ion-conductive polymer matrix. The effect of the cure degree is experimentally investigated by using $100 \%$ cure degree, $70 \%$ cure degree and $0 \%$ cure degree specimens. As a result, the polystyrene foam-core sandwich system is proved to be effective, but the capacitance is not enough because of the lack of surface area of the carbon fiber electrodes. As the remained TETA impedes the movement of $\mathrm{Li}^{+} \mathrm{Ca}-$ tion in the solid polymer by means of the segment-motion-assisted diffusion process, the low degree of cure causes small capacitance with this material system.
\end{abstract}

\section{Keywords}

Composites, Woven Carbon Fabric, Capacitor, Supercapacitor, Sandwich, Foam Core

\section{Introduction}

Structural capacitors are composite structures that function as energy storage capacitors. Luo and Chung have fabricated structural capacitors by using a paper separator [1] that exhibited as capacitance of $12 \mathrm{nF} / \mathrm{cm}^{2}$. Lin and Sodano made a cylindrical capa- 
citor by using piezoelectric material $\mathrm{BaTiO}_{3}$ that can be used as reinforcements of composites [2]. Carlson et al. used a paper and polymer sheet as dielectric separator of a capacitor, and obtained a capacitance of $25 \mathrm{nF} / \mathrm{cm}^{2}$ [3] [4]. O'Brien et al. also developed a parallel plate type structural capacitor [5]. The parallel plate type capacitor has advantage of the higher dielectric breakdown strength. The capacitor has, however, the drawback of the lower capacitance.

Shirshova et al. have developed an electric double layer capacitor (supercapacitor) of composite structures using electrolyte solid polymer matrix and glass fiber fabric separator [6] [7]. They obtained the capacitance of $8.9 \mathrm{mF} / \mathrm{cm}^{2}$. Qian et al. increased the surface area of the electrodes of the supercapacitor by using carbon aerogel [8], and they obtained the best capacitance of $640 \mathrm{mF} / \mathrm{cm}^{2}$. The supercapacitor enabled the higher capacitance of order of $1 \mathrm{~F} / \mathrm{cm}^{2}$, although the dielectric breakdown strength became smaller than that of a film type capacitor. The dielectric breakdown strength of a supercapacitor is approximately order of $1 \mathrm{~V}$, although the dielectric breakdown strength of the film capacitor is approximately order of $10 \mathrm{kV}$. As the extremely high voltage is not safe for regeneration-energy-storage capacitors in automobiles in service, the high capacitance of the supercapacitor is appropriate for the actual automobiles that require higher energy density compared with the film type capacitor. Therefore the structural supercapacitor is preferable for regenerated-energy storage of an automobile. The supercapacitor of a composite structure using electrolyte solid polymer matrix and glass fiber fabric separator, however, has a problem of electrical short between the carbon fiber plies because of the movement of glass fiber cloth during curing process [9].

In the present study, a new method to use foam core as a separator for a sandwich structural capacitor is proposed by using electrolyte polymer matrix to prevent the electrical short between the electrodes through the fabrication process. As a separator ply, a sandwich foam core is selected and experimentally confirmed to be effective. Moreover, the effect of the degree of cure of the electrolyte polymer matrix on the capacitance is also experimentally investigated.

\section{Concept of Foam-Core Sandwich Capacitor}

The concept of the foam-core-capacitor sandwich proposed in the present study is schematically shown in Figure 1 . The skin of the sandwich structure is woven fabric

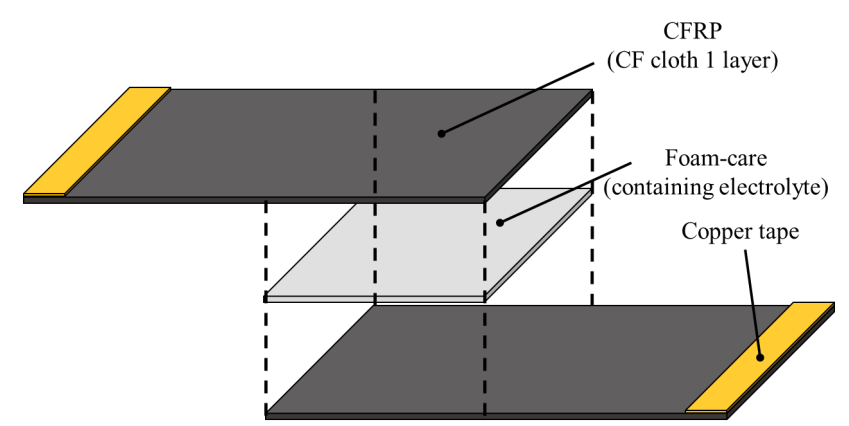

Figure 1. Schematic representation of a foam-core structural supercapacitor. 
carbon fiber reinforced polymer (CFRP) cloth. The skin woven fabric CFRP sheets play triple roles of structures, lead wires and electrodes of a capacitor. For the matrix of the CFRP, ion conductive solid polymer electrolyte is adopted.

\section{Fabrication of a Foam-Core Sandwich Capacitor}

Polystyrene foam core (moisture absorption type, Sekisui Plastic Co. Ltd, Osaka, Japan) is selected in the present study because of its higher liquid retentivity as shown in the reference [10]. PolyEthylene Glycol DiGlycidyl Ether (PEGDGE) with Lithium bisTriFluoromethaneSulfonylImide (LiTFSI) is selected as ion-conductive polymer and TriEthyleneTetrAmine (TETA) is adopted as harder as shown in the reference [7] [8]. The difference from the published papers is the selection of the foam core as a separator in the present study. To make sure that the polystyrene foam core can retain the ion-conductive polymer experimentally, red color ink is added into ion-conductive polymer PEGDGE with LiTFSI, and the red-colored PEGDGE with LiTFSI is immersed into the polystyrene foam core. Figure 2 shows the pre-investigation of this foam core. The red-colored PEGDGE with LiTFSI is immersed from the top surface of the polystyrene form core. The backside shows the polymer is partially immersed but not fully immersed. The ion-conductive polymer, therefore, is immersed from the both sides of the foam core. Figure 3 shows the cross sectional view of the immersed foam core from the both sides. Figure 3 shows the entire cross section is red. This means ion-conductive polymer is perfectly immersed into the polystyrene foam core.

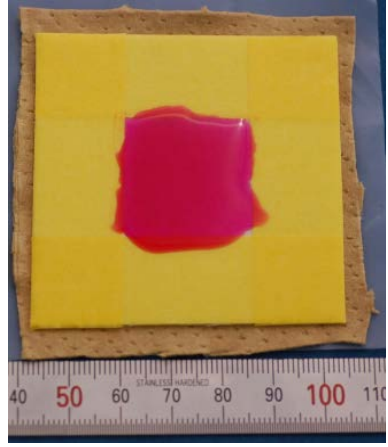

(a)

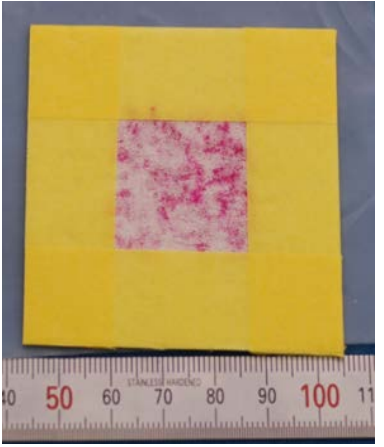

(b)

Figure 2. PEGDGE + LiTTFSI immersion test using red ink. (a) Top side of specimen; (b) Backside of specimen.

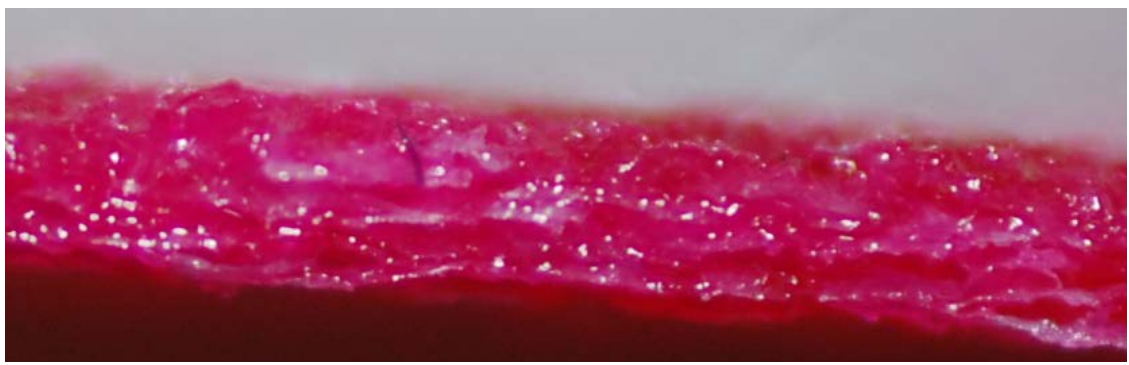

Figure 3. Cross sectional view of a polystyrene foam with red-colored PEGDGE with LiTTFS. 
Woven carbon fiber cloth (SA-3103, thickness $0.013 \mathrm{~mm}$, Sakaiovex Co. Ltd., Fukui Japan) was used as skin surface structure and lead wires. Polystyrene foam core (Sekisui plastics Co. Ltd., $0.8 \mathrm{~mm}$ thickness) was selected as a sandwich-foam core and a separator of a capacitor.

To make the ion-conductive polymer, a globe box is used to keep dry air condition. First, $10 \mathrm{~g}$ of PEGDGE was prepared and $0.1 \mathrm{~mol}$ LiTFSI is added into the PEGDGE. The PEGDGE with LiTFSi is mixed well using an agitator NBK-1 made by Nihonseiki Kaisha Ltd for five minutes at $200 \mathrm{rpm}$. After this, TriEthylene TetrAmine (TETA) was added at the mol ratio of PEGDGE:TETA $=4: 1$. The PEGDE with TETA was mixed for ten minutes at $200 \mathrm{rpm}$. Using this mixing process, the ion-conductive polymer was prepared as described in the reference [8].

The prepared ion-conducting polymer was immersed into the woven CF cloth and the foam core. The prepared woven CF cloth is $100 \mathrm{~mm}$ long and $50 \mathrm{~mm}$ wide. The 50 $\mathrm{mm}$ length of the woven CF cloth was used as electrodes for the structural capacitor. This means that the area of the capacitor is $50 \times 50\left(\mathrm{~mm}^{2}\right)$. The specimen was sandwiched by aluminum plates as shown in Figure 4 . The weight of the aluminum plates $(3.3 \mathrm{~kg})$ was loaded during the curing process. Figure 5 shows the specimen configuration.

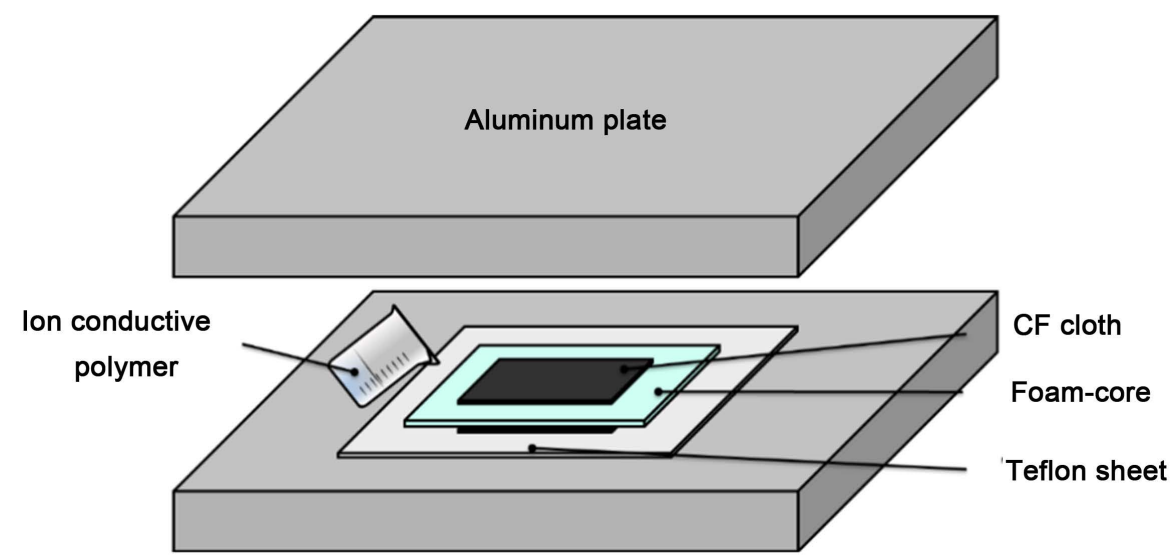

Figure 4. Manufacturing of CFRP structural capacitor using ion conductive polymer.

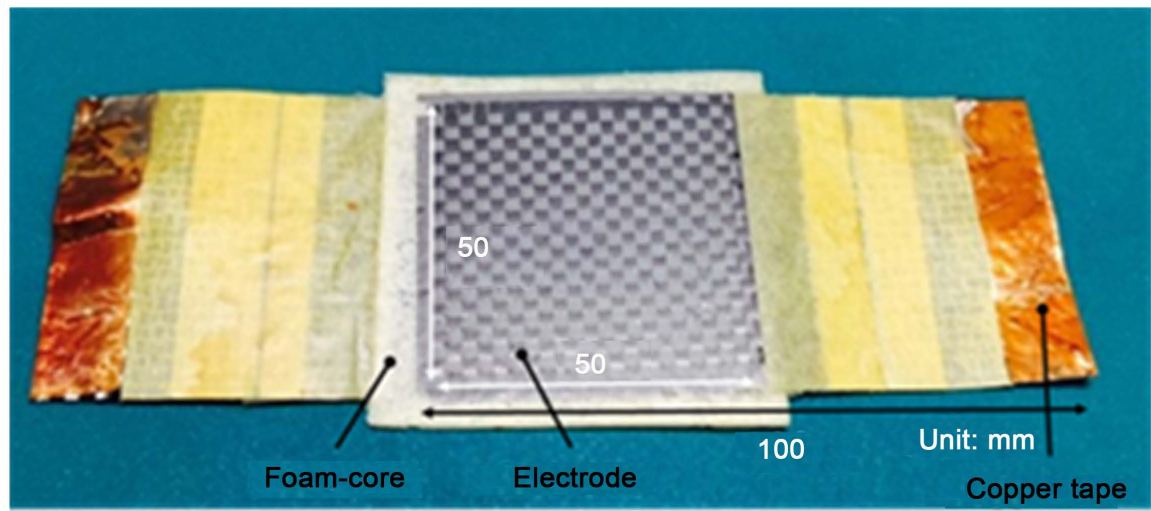

Figure 5. Specimen configuration. 


\section{Experimental Setup}

In the present study, three types of the degree of cure are investigated: $100 \%, 70 \%$ and 0\%. To measure the degree of cure, a Difference Scanning Calorimetry (DSC-60 Plus, Shimadzu Co., Kyoto, Japan) was used. To make a specimen of $100 \%$ degree of cure, the specimen was elevated at $1^{\circ} \mathrm{C} / \mathrm{min}$ up to $140^{\circ} \mathrm{C}$. To make a specimen of $70 \%$ of degree of cure, the specimen was elevated at $1^{\circ} \mathrm{C} / \mathrm{min}$ up to $75^{\circ} \mathrm{C}$. To make a specimen of $0 \%$ degree of cure, no curing process was performed. As it is difficult to control furnace temperature at lower temperature, specimens of the lower degree of cure was not prepared in the present study.

To measure the capacitance of the foam-core-sandwich supercapacitor specimen, the cyclic voltammetry method was employed. The cyclic voltammetry method uses constant rate voltage increase and decrease. The current is measured during sweeping the voltage. The capacitance $C(t)$ at time $t$ can be calculated as follows.

$$
C(t)=\frac{\int_{0}^{t} I(t) \mathrm{d} t}{V(t)}
$$

where $V(t)$ is the voltage at time $t$, and $I(t)$ is electric current at time $t$.

For the measurements of the capacitances, a versatile potentiostat/galvanostat machine Versastat 4 (Princeton Applied Research, Oak Ridge USA) was used. In the present study, the maximum voltage charged to the capacitor was set to $0.5 \mathrm{~V}$ to prevent dielectric breakdown of the electric double layer capacitor in the solid ion-conductive polymer. Since the low voltage causes the lower charged electric energy, the maximum limit voltage should be larger for actual usage. The maximum voltage can be improved using serial connection of the supercapacitor.

\section{Results and Discussion}

Figure 6 shows the result of the DSC at $1^{\circ} \mathrm{C} / \mathrm{min}$ up to $150^{\circ} \mathrm{C}$ test. The abscissa shows the temperature and the ordinate shows the measured reaction heat. The figure shows that the curing ended at the temperature of $131.8^{\circ} \mathrm{C}$. This experimental result reveals

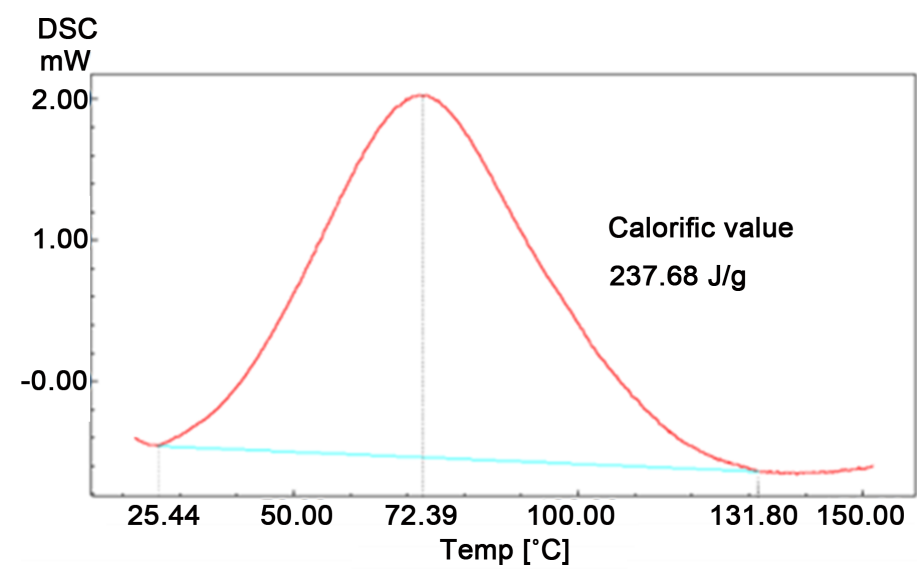

Figure 6. Measured DSC result at $1^{\circ} \mathrm{C} / \mathrm{min}$ up to $150^{\circ} \mathrm{C}$. 
that the $140^{\circ} \mathrm{C}$ at the rate of $1^{\circ} \mathrm{C} / \mathrm{min}$ is enough for $100 \%$ curing. After this test, the specimen temperature was elevated again with the DSC. The results showed that there is no curing reaction.

In order to obtain the specimen of $70 \%$ degree of cure, a specimen was heated at $1^{\circ} \mathrm{C} / \mathrm{min}$ up to $70^{\circ} \mathrm{C}$ and cooled down to the room temperature. During the process, the DSC is used to measure the heat reaction. The result is shown in Figure 7.

In Figure 7, the abscissa shows the time and the ordinate shows the measured reaction heat. The total reaction heat was measured from the elevation of the temperature to the cooling down to the room temperature. The degree of cure can be calculated as follow.

$$
1-\frac{71.3}{237.7}=0.7
$$

This shows the degree of cure is $70 \%$.

Figure 8 shows the measured results of the specimen of $100 \%$ cure using the voltammetry method. The abscissa is the charged voltage and the ordinate is the calculated capacitance obtained from the meas current. Let us consider the capacitance:

$$
Q=C V
$$

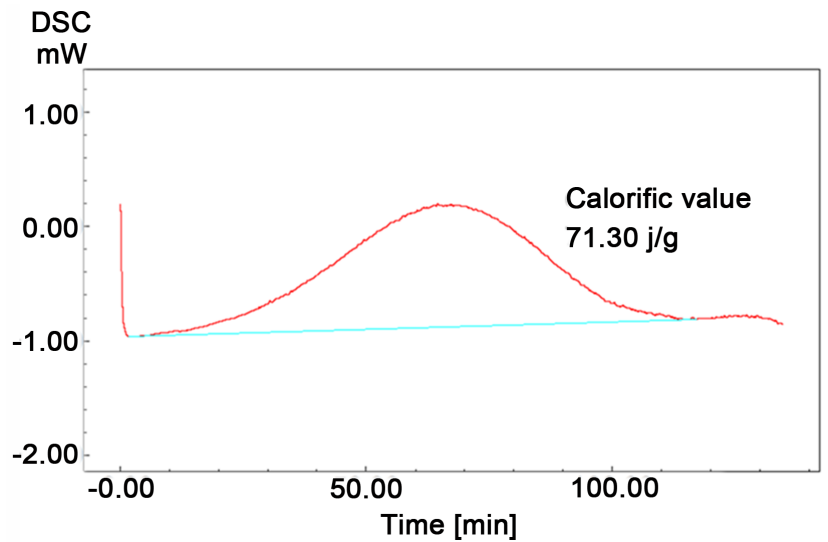

Figure 7. Measured DSC result $70 \%$ degree of curing test.

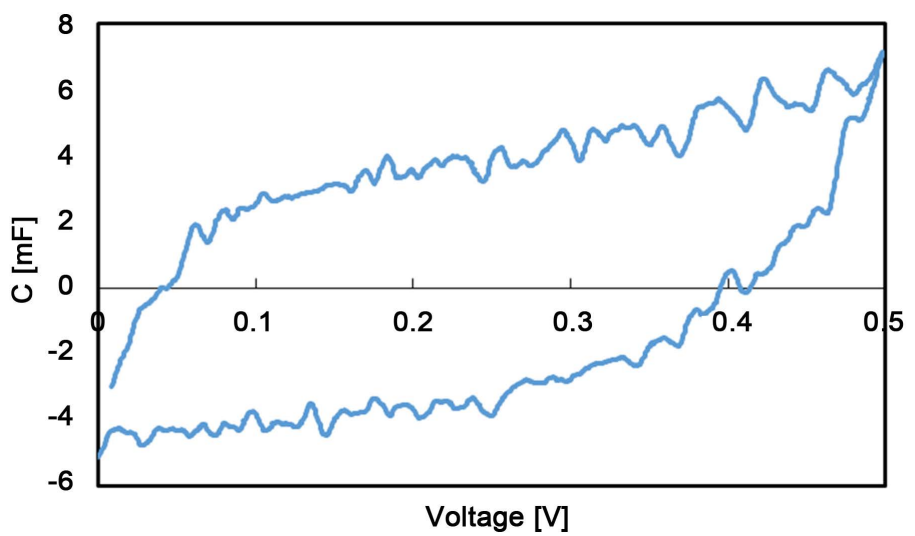

Figure 8. Measured results of the voltammetry method of $100 \%$ cure specimen. 


$$
I=\frac{\mathrm{d} Q}{\mathrm{~d} t}=C \frac{\mathrm{d} V}{\mathrm{~d} t}
$$

where $Q$ is electrical charge, $V$ is voltage, $C$ is capacitance, and $I$ is electric current. Equation (4) shows that capacitance can be easily calculated when the voltage change ratio $(\mathrm{d} V / \mathrm{d} t)$ is constant. The voltage change rate is $0.1 \mathrm{mV} / \mathrm{s}$ in the present study. Three cycles are performed to obtain the averaged capacitance. Figure 8 shows the electric current and voltage curve is almost rectangular shape.

In the present study, the capacitance was calculated using an increasing time period of voltage. The measured average capacitance is $3.66 \mathrm{mF}$. As the area used is $50 \mathrm{~mm} \times$ $50 \mathrm{~mm}=25 \mathrm{~cm}^{2}$, the capacitance per unit square centimeter is $0.146 \mathrm{mF} / \mathrm{cm}^{2}$. Although the capacitance is larger than that of film type capacitor, the capacitance is smaller than that of the research results obtained by Shirshova et al. [6]-[8]. This is because of the smaller surface area of carbon fibers at the electrodes. Shirshova et al. used special surface treatment of the carbon fibers to increase the surface area of the electrode carbon fibers. In the present study, the surface treatment was not performed.

Figure 9 shows the measured results of the specimen of $70 \%$ cure using the voltammetry method. The capacitance was calculated using increasing time period of voltage. The measured average capacitance is $2.57 \mathrm{mF}$. The capacitance is $30 \%$ decrease compared with that of $100 \%$ degree of cure. The specimen of $0 \%$ degree of cure shows no capacitance as shown in Figure 10. This means the degree of cure greatly affect the ionconductivity in this polymer.

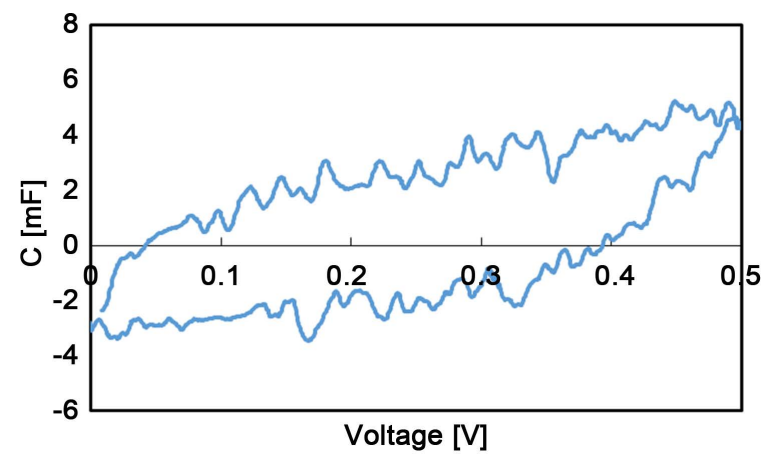

Figure 9. Measured results of the voltammetry method of $70 \%$ cure specimen.

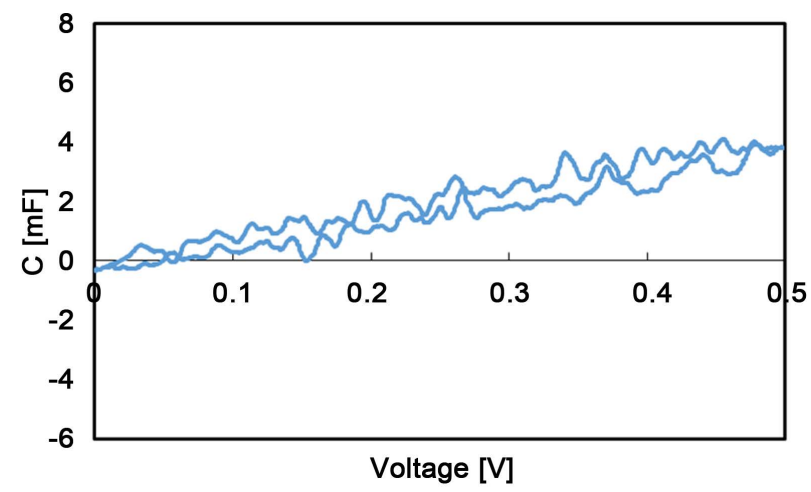

Figure 10. Measured results of the voltammetry method of $0 \%$ cure specimen. 
As shown in the reference [11], $\mathrm{Li}^{+}$cations are transported by the segmental-motionassisted diffusion process in solid polymer. When the degree of cure is low, this means the number of cross-links is small in the solid polymer. The long segments usually bring lower glass transition temperature [12]. This means the segment motion is easy when the degree of cure is low. Although the segment motion is easy when the degree of cure is low, the measured results show that the capacitance decreases along with the decrease of the degree of cure. This is because of the existence of the remained hardener TETA. TETA is amino group. The amino group has strong basicity [13], and this basicity impedes the diffusion movement of $\mathrm{Li}^{+}$cations. The selection of hardener is the important issue for the electrolyte solid polymer structural capacitor.

As the foam core plays a role of separator as shown in Figure 8, the polystyrene foam core is useful for the separator instead of the woven glass cloth that causes electrical short [9].

\section{Conclusion}

Experimental study shows that the polystyrene foam core is applicable as a separator for the structural capacitor. The foam core separator does not cause the electrical short during fabrication process. The degree of cure for PEGDGE with LiTFSI using TETA as hardener affects the capacitance significantly. Insufficient degree of cure causes remained harder TETA. The remained TETA impedes the movement of $\mathrm{Li}^{+}$cation in the solid polymer by means of the segment-motion-assisted diffusion process. To increase the capacitance, increase of the surface area of the electrodes is indispensable.

\section{Acknowledgements}

This research is supported by the JSPS Grants-in-Aid for scientific research of scientific research (part C) general FY2015 \#15K05673. This research was performed with the help of Mr. Kento Kawamura who was a student of Tokyo Institute of Technology. I would like to express sincerely thanks for his work.

\section{References}

[1] Luo, X. and Chung, D.D.L. (2001) Carbon-Fiber/Polymer Matrix Composites as Capacitors. Composites Science and Technology, 61, 885-888. http://dx.doi.org/10.1016/S0266-3538(00)00166-4

[2] Lin, Y. and Sodano, H.A. (2009) Characterization of Multifunctional Structural Capacitors for Embedded Energy Storage. Journal of Applied Physics, 106, 114108. http://dx.doi.org/10.1063/1.3267482

[3] Carlson, T., Ordéus, D., Wysocki, M. and Asp, L.E. (2010) Structural Capacitor Materials Made from Carbon Fibre Epoxy Composites. Composites Science and Technology, 70, 1135-1140. http://dx.doi.org/10.1016/j.compscitech.2010.02.028

[4] Carlson, T., Ordéus, D., Wysocki, M. and Asp, L.E., (2011) CFRP Structural Capacitor Materials for Automotive Application. Plastics, Rubber and Composites, 40, 311-316. http://dx.doi.org/10.1179/174328911X12948334590286

[5] O'Brien, D.J., Baechie, D.M. and Wetzel, E.D. (2011) Design and Performance of Multi- 
functional Structural Composite Capacitors. J. of Composite Materials, 45, 2797-2809.

http://dx.doi.org/10.1177/0021998311412207

[6] Shirshova, N., Qian H., Shaffer M.S.P., Steinke J.H.G., Greenhalgh, E.S., Curtis, P.T., Kucernak, A. and Bismarck, A. (2013) Structural Composite Supercapacitor. Composites. Part $A$, 46, 96-107. http://dx.doi.org/10.1016/j.compositesa.2012.10.007

[7] Shirshova, N., Bismarck, A., Carreyette, S., Fontana, Q.P.V., Greenhalgh, E.S., Jacobsson, P., Johansson, P., Marczewski, M.J., Kalinka, G., Kucernak, A.R.J., Sheers, J., Shaffer, M.S.P., Steinke, E.S. and Wienrich, M. (2013) Structural Supercapacitor Electrolytes Based on Bicontinuousionic Liquid-Epoxy Resin System. Journal of Materials Chemistry A, 1, 15300-15309. http://dx.doi.org/10.1039/c3ta13163g

[8] Qian, H., Kucernak, A.R.J., Greenhalgh, E.S., Bismarck, A. and Shaffer, M.S.P. (2013) Multifunctional Structural Supercapacitor Composites Based on Carbon Aerogel Modified High Performance Carbon Fiber Fabric. ACS Applied Materials and Interfaces, 5, 6113-6122.

[9] Todoroki, A., Shiomi, H., Mizutani, Y. and Suzuki, Y. (2014) Electrical Shorting between the Carbon-Fiber Cloth Electrodes of Structural Capacitors with a Glass-Fiber Cloth Separator. Open Journal of Composite Materials, 4, 140-147.

http://dx.doi.org/10.4236/ojcm.2014.43016

[10] Todoroki, A., Sawada, T., Mizutani, Y. and Suzuki, Y. (2015) Supercapacitor Consisting of a Form Core Sandwich with Woven Carbon Fiber Skin. Open Journal of Composite Materials, 5, 101-109. http://dx.doi.org/10.4236/ojcm.2015.54013

[11] Yang, M. and Hou, J. (2012) Membrances in Lithium Ion Batteries. Membrances, 2, 367383. http://dx.doi.org/10.3390/membranes2030367

[12] Wise, C.W., Cook, W.D. and Goodwin, A.A. (1997) Chemico-Diffusion Kinetics of Model Epoxy-Amine Resins. Polymer, 38, 3251-3261. http://dx.doi.org/10.1016/S0032-3861(96)00882-8

[13] McMurry, J. and Simanek, E. (2006) Fundamentals of Organic Chemistry. 6th Edition, Brooks/Cole Pub Co., Belmont.

Submit or recommend next manuscript to SCIRP and we will provide best service for you:

Accepting pre-submission inquiries through Email, Facebook, LinkedIn, Twitter, etc. A wide selection of journals (inclusive of 9 subjects, more than 200 journals)

Providing 24-hour high-quality service

User-friendly online submission system

Fair and swift peer-review system

Efficient typesetting and proofreading procedure

Display of the result of downloads and visits, as well as the number of cited articles Maximum dissemination of your research work

Submit your manuscript at: http://papersubmission.scirp.org/

Or contact ojcm@scirp.org 